\title{
Association of incidental emphysema with annual lung function decline and future development of airflow limitation
}

This article was published in the following Dove Press journal:

International Journal of COPD

29 January 2016

Number of times this article has been viewed

Hyeon-Kyoung Koo'

Kwang Nam Jin ${ }^{2}$

Deog Kyeom Kim ${ }^{3}$

Hee Soon Chung ${ }^{3}$

Chang-Hoon Lee ${ }^{3,4}$

'Department of Internal Medicine, Division of Pulmonary and Critical Care Medicine, College of Medicine, Ilsan Paik Hospital, Inje University, Goyang-si, Gyeonggi-Do, ${ }^{2}$ Department of Radiology, Seoul Metropolitan Government - Seoul National University Boramae Medical Center, ${ }^{3}$ Department of Internal Medicine, Division of Pulmonary and Critical Care Medicine, Seoul Metropolitan Government-Seoul National University Boramae Medical Center, ${ }^{4}$ Department of Internal Medicine, Division of Pulmonary and Critical Care Medicine, Seoul National University College of Medicine, Seoul National University Hospital, Seoul, Republic of Korea
Correspondence: Chang-Hoon Lee Department of Internal Medicine, Division of Pulmonary and Critical Care Medicine, Seoul National University College of Medicine, Seoul National University Hospital, I0I Daehak-Ro Jongno-Gu, Seoul 03080, Republic of Korea

Tel +82 220724743

Fax +82 27629662

Email kauri670@empal.com
Objectives: Emphysema is one of the prognostic factors for rapid lung function decline in patients with COPD, but the impact of incidentally detected emphysema on population without spirometric abnormalities has not been evaluated. This study aimed to determine whether emphysema detected upon computed tomography (CT) screening would accelerate the rate of lung function decline and influence the possibility of future development of airflow limitation in a population without spirometric abnormalities.

Materials and methods: Subjects who participated in a routine screening for health checkup and follow-up pulmonary function tests for at least 3 years between 2004 and 2010 were retrospectively enrolled. The percentage of low-attenuation area below -950 Hounsfield units $\left(\% \mathrm{LAA}_{-950}\right)$ was calculated automatically. A calculated value of $\% \mathrm{LAA}_{-950}$ that exceeded $10 \%$ was defined as emphysema. Adjusted annual lung function decline was analyzed using randomslope, random-intercept mixed linear regression models.

Results: A total of 628 healthy subjects within the normal range of spriometric values were included. Multivariable analysis showed that the emphysema group exhibited a faster decline in forced vital capacity ( -33.9 versus $-18.8 \mathrm{~mL} /$ year; $P=0.02$ ). Emphysema was not associated with the development of airflow limitation during follow-up.

Conclusion: Incidental emphysema quantified using CT scan was significantly associated with a more rapid decline in forced vital capacity in the population with normative spirometric values. However, an association between emphysema and future development of airflow limitation was not observed.

Keywords: annual decline rate, respiratory function tests, pulmonary emphysema, chronic obstructive pulmonary disease

\section{Introduction}

Lung function declines with age, ${ }^{1}$ but certain factors accelerate this rate of decline, ${ }^{2,3}$ one of which is chronic obstructive pulmonary disease (COPD). COPD is characterized by persistent airflow limitation associated with a mixture of small airway inflammation (obstructive bronchiolitis) and parenchymal destruction (emphysema). ${ }^{2,4}$ Emphysema is reported to be a prognostic factor for higher mortality rates in COPD patients, ${ }^{5,6}$ but the influence of emphysema on the rate of lung function decline is controversial. ${ }^{7-11}$ In Korea, regular health checkup, including computed tomography (CT) screening, is frequently performed because of increased concern over one's health status and highly accessible medical sources with low economic burden. Consequently, the incidental detection of asymptomatic emphysema has increased. However, according to the current Global Initiative for Chronic Obstructive Lung Disease (GOLD) guideline, classification and treatment of COPD are based on pulmonary function test (PFT) results. 
Therefore, guidance for populations with emphysema without spirometric abnormalities is not included in the current guideline. There is limited knowledge about the natural course in this population, and whether emphysema affects the rate of decline of lung function or future development of airflow limitation remains undetermined. In addition, many previous studies classify the severity of emphysema on the basis of visual assessment by a small number of radiologists to minimize interobserver variability. ${ }^{7,10}$ However, poor agreement between radiologists in the visual grading of emphysema has been reported. ${ }^{12}$ Therefore, quantification of emphysema by objective computerized software may improve the reproducibility. ${ }^{13}$

The aim of our study was to investigate the association among emphysema quantified by computerized software, the annual decline rate of lung function, and the development of airflow limitation in a population within the normal range of pulmonary function.

\section{Materials and methods}

\section{Study participants}

Healthy participants who underwent voluntary baseline CT scans for routine health checkup at Seoul Metropolitan Government - Seoul National University Boramae Medical Center in South Korea and follow-up PFTs for at least 3 years, between January 2004 and December 2010, were retrospectively included. Subjects with known respiratory disease or abnormal PFT results at baseline, including cases with forced expiratory volume in 1 second $\left(\mathrm{FEV}_{1}\right) /$ forced vital capacity $(\mathrm{FVC})<0.7, \mathrm{FEV}_{1}<80 \%$ predicted, or $\mathrm{FVC}<80 \%$ predicted, were excluded. Participants were asked to complete a short questionnaire on respiratory symptoms, smoking history, and medical history. Clinical information including age, sex, height, weight, abdominal circumference, smoking status, smoking amount, other underlying diseases, values of PFT results, and CT image findings were also reviewed. Informed consent was waived due to the retrospective design, and patient records were anonymized and de-identified prior to analysis. The Institutional Review Boards of Seoul Metropilitan Government - Seoul National University Boramae Medical Center, Seoul, Republic of Korea, approved this study (IRB no: 20110407/06-2011-67/106).

\section{Pulmonary function testing}

All the spirometry tests were conducted using standardized equipment (model 1022; SensorMedics Corp, BD, Franklin Lakes, NJ, USA) by two qualified technicians following the American Thoracic Society/European Respiratory Society guidelines. ${ }^{14}$ Spirometry was repeated at least three times to ensure reproducibility and validity. Calculation of PFT values, in relation to reference values, was performed using computer programs and reviewed by trained physicians. Reference values were calculated using Morris's predictive equation. ${ }^{15,16}$ As only participants without spirometric abnormalities were enrolled in the study, postbronchodilator testing was not performed, and all measures were based on prebronchodilator values. COPD was defined as occurrence of airflow limitation $\left(\mathrm{FEV}_{1} / \mathrm{FVC}<0.7\right)$ during the follow-up period according to GOLD statements.

\section{CT protocol and image analysis}

The baseline chest CT scans were used for analysis, which were obtained using a low-radiation dose technique without intravenous contrast material. Chest CT scans were acquired in the supine position with breath held at full inspiration by using a LightSpeed Pro 16 (General Electric Medical Systems, Milwaukee, WI, USA). Technical parameters were as follows: 40-60 mAs, $120 \mathrm{kVp}$ tube voltage, and $360 \mathrm{~mm}$ field of view. Effective milliampere-second was selected based on the patients' body mass index (BMI) $\left(40 \mathrm{mAs}\right.$ for BMI $\leq 30 \mathrm{~kg} / \mathrm{m}^{2}$ and $60 \mathrm{mAs}$ for BMI $\left.>30 \mathrm{~kg} / \mathrm{m}^{2}\right)$. Tube current modulation or iterative reconstruction was not used. The scan was performed from the lung apex to diaphragm, and respiratory gating was not used. Transverse data sets were reconstructed with $2.5 \mathrm{~mm}$ thickness at $2.5 \mathrm{~mm}$ increments, using a standard reconstructing algorithm. The percentage of the low-attenuation area (\%LAA), which indicates emphysematous destruction, was automatically calculated by Extended Brilliance Workspace (Version 3.0; Philips, Best, The Netherlands). As -950 Hounsfield units (HU) has been suggested to be the optimal threshold for quantification of emphysematous destruction, ${ }^{17,18}$ the extent of low-attenuation area below -950 HU (\% $\left.\% \mathrm{LAA}_{-950}\right)$ was measured for emphysema scoring. Emphysema was defined as calculated emphysema scores $\left(\% \mathrm{LAA}_{-950}\right)$ exceeding $10 \%$, which was the same criteria used in the COPDGene and ECLIPSE cohort studies. ${ }^{19}$ Several studies also showed an increased mortality in cases with \% LAA $_{-950}>10 \%{ }^{5,6}$ Since minimal differences were reported in the quantification of emphysema between standard radiation dose and low radiation dose $\mathrm{CT}$ techniques, we used values of emphysema scoring calculated from our low radiation dose CT protocol without modification, which is fitted for lung cancer screening. ${ }^{20-23}$

\section{Statistical analysis}

A Student's $t$-test was used to compare continuous variables, and chi-square tests were used for between-group comparisons. The effects of emphysema on the $\mathrm{FEV}_{1}$ or $\mathrm{FVC}(\mathrm{mL} / \mathrm{year})$ 
annual decline rate were analyzed using a random-slope, random-intercept mixed linear regression model with variables including emphysema, time of visit in years, and emphysemaby-time interaction and covariates including age, sex, height, BMI, smoking status, and baseline $\mathrm{FEV}_{1}$ or FVC. ${ }^{24-29}$ The occurrence of airflow limitations was calculated using the Kaplan-Meier method, and Cox proportional hazards regression was used to assess risk factors for multivariate analysis. All statistical analyses were performed using Stata (Stata 13.1; StataCorp LP, College Station, TX, USA) and SPSS software (Version 12.0K; SPSS Inc., Chicago, IL, USA).

\section{Results}

\section{Baseline characteristics}

A total of 628 subjects who met the inclusion criteria were enrolled in the study; 474 (75.5\%) were males and $271(43.2 \%)$ were current smokers (Figure 1). The baseline median age was 48 years (interquartile range [IQR], 40-56). The mean PFT values were as follows: FVC,

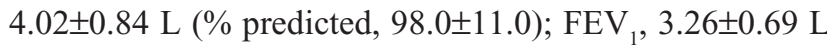
(\% predicted, 105.7 \pm 12.4 ); and $\mathrm{FEV}_{1} / \mathrm{FVC}, 81.2 \% \pm 5.5 \%$. The median \%LAA ${ }_{-950}$ was 1.8\% (IQR, 0.6-7.0). Eightyfive subjects $(13.5 \%)$ were allocated to the emphysema group (\%LAA $\left.{ }_{-950}>10 \%\right)$. The participants' demographic and clinical characteristics including pulmonary functions are summarized in Table 1. Emphysema score $\left(\%\right.$ LAA $\left._{-950}\right)$ was not significantly associated with baseline spirometric pulmonary function or smoking amount.

\section{Annual decline rate of lung function and occurrence of COPD: longitudinal analysis}

The median follow-up period was 4 years (IQR, 3-5), and the median number of spirometry tests was three (IQR, 2-4). The adjusted annual rate of $\mathrm{FEV}_{1}$ decline was apparently higher in the emphysema group, but the difference was not statistically significant $(-26.3 \pm 5.7$ versus $-17.5 \pm 2.6 \mathrm{~mL} /$ year; mean difference, $8.8 \mathrm{~mL} /$ year; $P=0.14$ ). The adjusted annual rate of FVC decline was significantly higher in the emphysema group $(-18.8 \pm 2.4$ versus $-33.9 \pm 6.0 \mathrm{~mL} /$ year; mean difference, $15.2 \mathrm{~mL} /$ year; $P=0.02$ ). There were no statistically significant differences in the adjusted annual rate of $\mathrm{FEV}_{1} / \mathrm{FVC}$ decline between the two groups ( $P=0.35$; Table 2). Sex (FVC, $P=0.37$; $\mathrm{FEV}_{1}, P=0.08$ ), obesity (FVC, $P=0.64$ FEV $_{1}, P=0.73$ ), and abdominal obesity (FVC, $P=0.33 ; \mathrm{FEV}_{1}, P=0.85$ ) were not significantly associated with the rate of lung function decline. History of smoking exhibited a tendency toward accelerated annual rate of $\mathrm{FEV}_{1}$ decline $(-15.0$ versus $-21.0 \mathrm{~mL} /$ year), although not statistically significant $(P=0.15)$, and had no influence on the annual rate of FVC decline $(-20.9$ versus $-20.4 \mathrm{~mL} /$ year; $P=0.91)$. As smoking is an important risk factor for COPD,${ }^{30}$ we compared the subgroup characteristics according to smoking status. In the current-smoker subgroup, the presence of emphysema did not demonstrate statistically significant difference in the adjusted annual decline rates of $\mathrm{FVC}(P=0.50)$ and $\mathrm{FEV}_{1}(P=0.79)$. However, the adjusted annual rate of FVC decline was significantly accelerated by the presence of emphysema in the noncurrentsmoker subgroup $(-18.0 \pm 3.0$ versus $-35.8 \pm 6.7 \mathrm{~mL} /$ year; mean difference, $17.8 \mathrm{~mL} /$ year; $P=0.02$ ), while the adjusted annual rate of $\mathrm{FEV}_{1}$ decline also showed a tendency toward acceleration with emphysema but did not reach statistical significance $(-18.2 \pm 3.3$ versus $-30.3 \pm 6.4 \mathrm{~mL} /$ year; mean difference, $12.1 \mathrm{~mL} /$ year; $P=0.07)$.

Occurrence of airflow limitation $\left(\mathrm{FEV}_{1} / \mathrm{FVC}<0.7\right)$ during follow-up was observed in $5.5 \%$ of participants without emphysema and $4.7 \%$ of participants with emphysema. Kaplan-Meier analysis revealed that emphysema was not

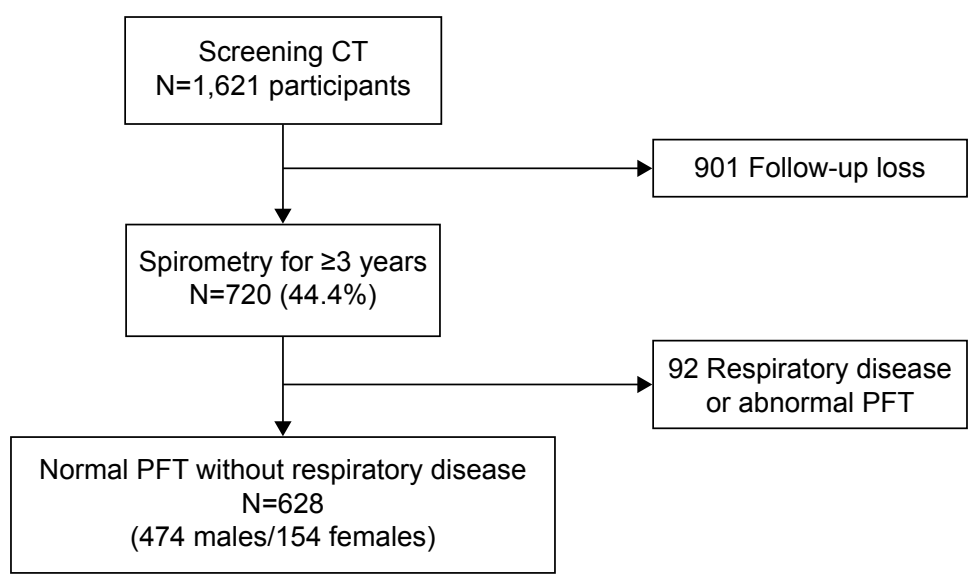

Figure I Flowchart describing recruitment of study population.

Abbreviations: CT, computed tomography; PFT, pulmonary function test. 
Table I Baseline characteristics at the initial visit

\begin{tabular}{|c|c|c|c|c|}
\hline & Total & Emphysema (-) & Emphysema (+) & $P$-value \\
\hline$N$ & 628 & 543 & 85 & \\
\hline Age (years), median (QI, Q3) & $48(40,56)$ & $48(40,56)$ & $49(42.5,56)$ & 0.16 \\
\hline Male sex & 474 (75.5\%) & $403(74.2 \%)$ & 71 (83.5\%) & 0.08 \\
\hline Height $(\mathrm{cm})$ & $166.8 \pm 8.5$ & $166.7 \pm 8.7$ & $168.0 \pm 7.1$ & 0.12 \\
\hline Body weight (kg) & $67.1 \pm 10.9$ & $66.8 \pm 10.9$ & $69.0 \pm 10.3$ & 0.10 \\
\hline BMI & $24.0 \pm 3.0$ & $24.0 \pm 2.9$ & $24.4 \pm 3.3$ & 0.21 \\
\hline Current smoker & $27 \mathrm{I}(43.2 \%)$ & $24 I(44.4 \%)$ & $30(35.3 \%)$ & 0.13 \\
\hline \multicolumn{5}{|l|}{ Noncurrent smoker } \\
\hline Ex-smoker & $150(23.9 \%)$ & $|2|(22.3 \%)$ & 29 (34.1\%) & 0.71 \\
\hline Never smoker & $207(33.0 \%)$ & $181(33.3 \%)$ & $26(30.6 \%)$ & \\
\hline Pack years, median (QI,Q3) & $10.0(0,22.5)$ & $10.0(0,22.5)$ & $8.5(0,20)$ & 0.87 \\
\hline FU duration (years) & $3.1 \pm 1.4$ & $3.1 \pm 1.4$ & $3.2 \pm 1.4$ & 0.87 \\
\hline \multicolumn{5}{|l|}{ PFT } \\
\hline FVC (L) & $4.02 \pm 0.84$ & $4.00 \pm 0.84$ & $4.18 \pm 0.82$ & 0.06 \\
\hline FVC (\% predicted) & $98.0 \pm 11.0$ & $97.7 \pm 10.8$ & $99.9 \pm 12.1$ & 0.08 \\
\hline $\mathrm{FEV}_{1}(\mathrm{~L})$ & $3.26 \pm 0.69$ & $3.24 \pm 0.68$ & $3.38 \pm 0.70$ & 0.09 \\
\hline $\mathrm{FEV}_{1}$ (\% predicted) & $105.7 \pm 12.4$ & $105.3 \pm 12.5$ & $107.9 \pm 12.2$ & 0.08 \\
\hline $\mathrm{FEV}_{1} / \mathrm{FVC}(\%)$ & $81.2 \pm 5.5$ & $81.3 \pm 5.5$ & $80.7 \pm 5.5$ & 0.37 \\
\hline${ }_{\% L_{A}}{ }_{-950}, \operatorname{median}(\mathrm{Q}, \mathrm{Q} 3)$ & I.8 $(0.6,7.0)$ & I.3 $(0.5,4.3)$ & I3.3 (II.2, |7.3) & $<0.001$ \\
\hline
\end{tabular}

Note: \% LAA $_{-950}$ is the percentage of low-attenuation area below -950 Hounsfield units measured by computed tomography quantification.

Abbreviations: N, Number; QI, first quartile; Q3, third quartile; BMI, body mass index; FU, follow-up; PFT, pulmonary function test; FVC, forced vital capacity; FEV , forced expiratory volume in I second.

associated with the development of airflow obstruction (logrank test, $P=0.76$; Figure 2). Multivariable Cox proportional hazards regression model adjusted for age, sex, height, BMI, and current smoking status showed that emphysema was also not a significant predictor for development of airflow limitation $(P=0.47)$. There was no statistically significant interaction between emphysema and current smoking status ( $P=0.98)$ for the development of airflow limitation.

\section{Discussion}

In South Korea, possibly owing to low medical costs and increase in attention to health status, CT screening for medical checkup has recently become popular. ${ }^{31}$ Physicians often encounter incidental emphysema cases detected on CT without spirometric abnormalities. For the first time, our study shows that emphysema found incidentally was associated with a more rapid decline of lung function, particularly FVC. Although a statistically significant difference was not found, the emphysema group showed a faster decline in $\mathrm{FEV}_{1}$ (adjusted mean $\mathrm{FEV}_{1}$ decline rate: $-26.3 \mathrm{~mL} /$ year), which was slightly lower than that of COPD patients in the ECLIPSE cohort ( $-33 \mathrm{~mL} /$ year) ${ }^{32}$ In fact, previous studies with COPD patients ${ }^{8,11}$ report that emphysema is a risk factor for the rapid decline of $\mathrm{FEV}_{1}$. However, in our study, incidental emphysema did not increase the risk of detection of airflow limitation during follow-up. This was because the rate of decline in FVC (mean difference in slope, $-15.2 \mathrm{~mL} /$ year; $P$ for interaction, 0.029$)$ was more significant than the rate of decline in $\mathrm{FEV}_{1}$ (mean difference in slope, $-8.8 \mathrm{~mL} /$ year; $P$ for interaction, 0.153). Similarly, Mohamed Hoesein et al reported that a one-point decrease in total lung emphysema severity was associated with a $64 \mathrm{~mL} /$ year decline in $\mathrm{FEV}_{1}$ and a $165 \mathrm{~mL} /$ year decline in $\mathrm{FVC}^{33}$

A plausible mechanism for the more significant decline in FVC is not clear, but it could be explained by an increase in residual volume by hyperinflation. As emphysema is known

Table 2 Adjusted decline rate of lung function according to the presence of emphysema

\begin{tabular}{|c|c|c|c|c|c|c|c|c|c|c|c|c|}
\hline \multirow[t]{2}{*}{ Total* } & \multicolumn{4}{|l|}{ FEV } & \multicolumn{4}{|l|}{ FVC } & \multicolumn{4}{|c|}{ 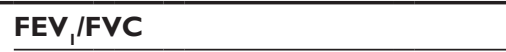 } \\
\hline & $\mathrm{mL} / \mathrm{yr}$ & SE & Mean difference & $P$-value & $\mathrm{mL} / \mathrm{yr}$ & SE & Mean difference & $P$-value & $\mathrm{mL} / \mathrm{yr}$ & SE & Mean difference & $P$-value \\
\hline $\begin{array}{l}\text { Emphysema }(-) \\
(\mathrm{n}=543)\end{array}$ & -17.5 & 2.6 & $8.8(-2.7,20.3)$ & 0.14 & -18.8 & 2.4 & I5.2 (2.6, 27.8) & 0.02 & -0.45 & 0.05 & $0.12(-0.2,0.4)$ & 0.35 \\
\hline $\begin{array}{l}\text { Emphysema }(+) \\
(\mathrm{n}=85)\end{array}$ & -26.3 & 5.7 & & & -33.9 & 6.0 & & & -0.34 & 0.11 & & \\
\hline
\end{tabular}

Note: *Adjusted by age, sex, height, BMI, current smoking status, and baseline PFT.

Abbreviations: $\mathrm{FEV}_{1}$, forced expiratory volume in I second; FVC, forced vital capacity; yr, year; SE, standard error; BMI, body mass index; PFT, pulmonary function test. 


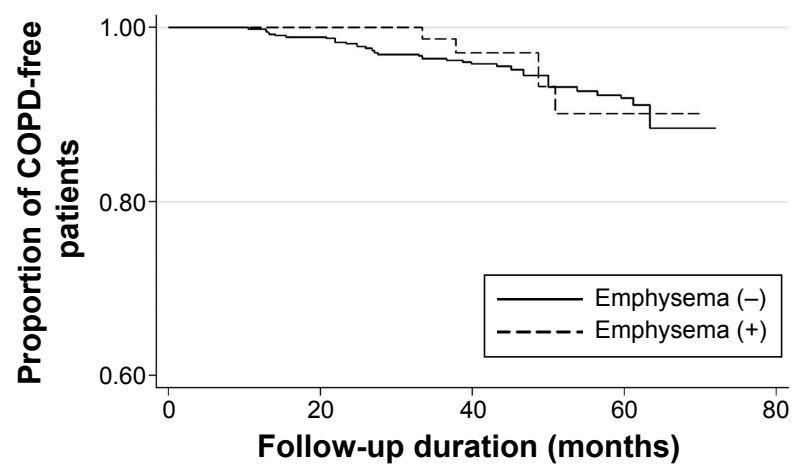

Figure 2 Occurrence of airflow limitation rate during follow-up according to the presence of emphysema.

to be a characteristic pathological finding in COPD patients, ${ }^{2}$ it contributes to airflow limitation by the mechanism of the equal pressure point theory: loss of elastic recoil contracting the airway and increase in expiration time. ${ }^{34}$ Airflow limitation induces hyperinflation in emphysema patients, and the increased residual volume can decrease the functional residual capacity and further cause FVC to decrease. Therefore, we cannot assume that emphysema is not associated with further lung function aggravation just because we did not find an association between the presence of emphysema and the future development of airflow limitation.

Our study had several strengths. This study targeted the population with emphysema but normal spirometric values. Previously, subjects with morphological emphysema but no definite spirometric abnormalities were excluded in COPD studies based on current diagnostic criteria. Yuan et al performed a similar study on 143 subjects without airflow limitations. However, they did not reveal the relationship between emphysema on $\mathrm{CT}$ and the annual rate of $\mathrm{FEV}_{1}$ decline, although only half of the participants were scanned twice, and the difference in the annual FVC decline rates was also not analyzed. ${ }^{9}$ More recently, a subgroup analysis of cohorts for the Dutch Belgian Randomized Lung Cancer Screening Trial (NELSON) was reported; the study subjects included 1,391 participants without airflow limitation on baseline spirometry. PFTs were performed twice, and the subjects who later developed airway obstruction had lower HU point below which $15 \%$ of the voxels are distributed (Perc 15). ${ }^{11}$ However, this study did not evaluate the FVC decline rate, and patients with restrictive lung diseases were included in this subgroup. Compared with previous reports, our study included a larger number of subjects in this population with a longer follow-up duration. The annual decline rate of $\mathrm{FEV}_{1}$ in the emphysema group in our study was similar to that of COPD controls $(-30 \mathrm{~mL} /$ year $)$ in the
UPLIFT trial. ${ }^{25}$ Thus, the lung function of this population with incidentally detected emphysema actually declined rapidly, similar to COPD patients. However, owing to a simultaneous decrease in FVC, airflow obstruction was not detected during follow-up in the majority of this population. As these patients with emphysema may not be diagnosed with COPD by spirometry, they may miss opportunities for intervention. Out study emphasizes the importance of asymptomatic emphysema irrespective of PFT results. In addition, we quantified emphysema using an automatic computerized system to control discrepancies between observers. Previous studies usually measured the extent of emphysema by visual assessment, despite a report that visual assessment of emphysema revealed low inter- and intra-operator agreement. ${ }^{12}$ The results with computerized software could be applied to many other centers with high reproducibility.

For the correct interpretation of the present results, the limitation of this study should be noted. First, we did not compare the baseline characteristics among subjects who did not attend follow-up spirometry, and this could have led to bias from loss to follow-up, particularly in the emphysema group. Second, a notable number of nonsmokers were included in the emphysema group in our population; this could be explained by other causes of lung injury, such as exposure to biomass fumes and respiratory infection. ${ }^{35}$ However, we could not get the complete information about these other causes. For example, we do not have information about history of residence, which was associated with the degree of exposure to air pollution. Third, we did not evaluate postbronchodilator $\mathrm{FEV}_{1}$ and $\mathrm{FVC}$, which are more commonly used as lung function variables in COPD patients. ${ }^{3,36}$ However, as our study enrolled only subjects with normative values of pulmonary function at initial spirometry, this could be somewhat overlooked. Fourth, although we enrolled the study population retrospectively, there are still some concerns about radiation hazard. Fifth, we could not find a plausible mechanism for the rapid decline in FVC. To understand the natural course of the emphysema population with a normal range of PFT results, further detailed larger trials are needed to evaluate their role in COPD progression, exacerbation, and mortality.

\section{Conclusion}

Although quantified emphysema without spirometric abnormalities was not associated with future development of airflow limitation, it was significantly associated with a more rapid decline in FVC. 


\section{Disclosure}

The authors report no conflicts of interest in this work.

\section{References}

1. Janssens JP, Pache JC, Nicod LP. Physiological changes in respiratory function associated with ageing. Eur Respir J. 1999;13:197-205.

2. Roisin RR. Global Strategy for the Diagnosis, Management and Prevention of COPD Updated 2011. 2015. Available from: http://www. goldcopd.org. Accessed November 26, 2015.

3. Ito K, Barnes PJ. COPD as a disease of accelerated lung aging. Chest. 2009; 135:173-180.

4. Hogg JC. Pathophysiology of airflow limitation in chronic obstructive pulmonary disease. Lancet. 2004;364:709-721.

5. Zulueta JJ, Wisnivesky JP, Henschke CI, et al. Emphysema scores predict death from COPD and lung cancer. Chest. 2012;141:1216-1223.

6. Johannessen A, Skorge TD, Bottai M, et al. Mortality by level of emphysema and airway wall thickness. Am J Respir Crit Care Med. 2013;187: 602-608.

7. Stolk J, Putter H, Bakker EM, et al. Progression parameters for emphysema: a clinical investigation. Respir Med. 2007;101:1924-1930.

8. Nishimura M, Makita H, Nagai K, et al; Hokkaido COPD Cohort Study Investigators. Annual change in pulmonary function and clinical phenotype in chronic obstructive pulmonary disease. Am J Respir Crit Care Med. 2012;185:44-52.

9. Yuan R, Hogg JC, Paré PD, et al. Prediction of the rate of decline in FEV(1) in smokers using quantitative computed tomography. Thorax. 2009; 64:944-949.

10. Remy-Jardin M, Edme JL, Boulenguez C, et al. Longitudinal follow-up study of smoker's lung with thin-section CT in correlation with pulmonary function tests. Radiology. 2002;222:261-270.

11. Hoesein MFA, de Hoop B, Zanen P, et al. CT quantified emphysema in male heavy smokers: association with lung function decline. Thorax. 2011;66:782-787.

12. Mascalchi M, Diciotti S, Sverzellati N, et al. Low agreement of visual rating for detailed quantification of pulmonary emphysema in whole-lung CT. Acta Radiol. 2012;53:53-60.

13. Gould GA, MacNee W, McLean A, et al. CT measurements of lung density in life can quantitate distal airspace enlargement-an essential defining feature of human emphysema. Am Rev Respir Dis. 1988;137:380-392.

14. American Thoracic Society. Single-breath carbon monoxide diffusing capacity (transfer factor). Recommendations for a standard technique 1995 update. Am J Respir Crit Care Med. 1995;152:2185-2198.

15. Morris JF, Koski A, Johnson LC. Spirometric standards for healthy nonsmoking adults. Am Rev Respir Dis. 1971;103:57-67.

16. Lee $\mathrm{CH}$, Lee JY, Jang EJ, et al. New predictive equations for spirometric reference values and comparison with Morris equation in a Korean population. Respirology. 2008;13:365-371.

17. Gevenois PA, De Vuyst P, de Maertelaer V, et al. Comparison of computed density and microscopic morphometry in pulmonary emphysema. Am J Respir Crit Care Med. 1996;154:187-192.

18. Wang Z, Gu S, Leader JK, et al. Optimal threshold in CT quantification of emphysema. Eur Radiol. 2013;23:975-984.

19. Hersh CP, Make BJ, Lymch DA, et al. None-emphysematous chronic obstructive pulmonary disease is associated with diabetes mellitus. BMC Pulm Med. 2014;14:164.
20. Gierada DS, Pilgram TK, Whiting BR, et al. Comparison of standardand low-radiation-dose CT for quantification of emphysema. AJR Am J Roentgenol. 2007;188(1):42-47.

21. Wang R, Sui X, Schoepf UJ, et al. Ultralow-radiation-dose chest CT: accuracy for lung densitometry and emphysema detection. AJR Am J Roentgenol. 2015;204(4):743-749.

22. Hague CJ, Krowchuk N, Alhassan D, et al. Qualitative and quantitative assessment of smoking-related lung disease: effect of iterative reconstruction on low-dose computed tomographic examinations. J Thorac Imaging. 2014;29(6):350-356.

23. Mets OM, Schmidt M, Buckens CF, et al. Diagnosis of chronic obstructive pulmonary disease in lung cancer screening computed tomography scans: independent contribution of emphysema, air trapping and bronchial wall thickening. Respir Res. 2013;14:59.

24. Celli BR, Thomas NE, Anderson JA, et al. Effect of pharmacotherapy on rate of decline of lung function in chronic obstructive pulmonary disease: results from the TORCH study. Am J Respir Crit Care Med. 2008; 178:332-338.

25. Decramer M, Celli B, Kesten S, et al; UPLIFT Investigators. Effect of tiotropium on outcomes in patients with moderate chronic obstructive pulmonary disease (UPLIFT): a prespecified subgroup analysis of a randomised controlled trial. Lancet. 2009;374:1171-1178.

26. Tashkin DP, Celli B, Senn S, et al; UPLIFT Study Investigators. A 4-year trial of tiotropium in chronic obstructive pulmonary disease. N Engl J Med. 2008;359:1543-1554.

27. Pauwels RA, Löfdahl CG, Laitinen LA, et al. Long-term treatment with inhaled budesonide in persons with mild chronic obstructive pulmonary disease who continue smoking. European respiratory society study on chronic obstructive pulmonary disease. N Engl J Med. 1999; 340:1948-1953.

28. Lung Health Study Research Group. Effect of inhaled triamcinolone on the decline in pulmonary function in chronic obstructive pulmonary disease. N Engl J Med. 2000;343:1902-1909.

29. Burge PS, Calverley PM, Jones PW, et al. Randomised, double blind, placebo controlled study of fluticasone propionate in patients with moderate to severe chronic obstructive pulmonary disease: the ISOLDE trial. BMJ. 2000;320:1297-1303.

30. Fletcher C, Peto R. The natural history of chronic airflow obstruction. Br Med J. 1977;1:1645-1648.

31. Ahn HS, Kim HJ, Welch HG. Korea's thyroid-cancer "epidemic"-screening and overdiagnosis. N Engl J Med. 2014;371(19):1765-1767.

32. Vestbo J, Edwards LD, Scanlon PD, et al; ECLIPSE Investigators. Changes in forced expiratory volume in 1 second over time in COPD. N Engl J Med. 2011;365:1184-1192.

33. Mohamed Hoesein FA, van Rikxoort E, van Ginneken B, et al. Computed tomography-quantified emphysema distribution is associated with lung function decline. Eur Respir J. 2012;40:844-850.

34. Mead J, Turner JM, Macklem PT, et al. Significance of the relationship between lung recoil and maximum expiratory flow. J Appl Physiol. 1967; 22:95-108.

35. Salvi SS, Barnes PJ. Chronic obstructive pulmonary disease in nonsmokers. Lancet. 2009;374:733-743.

36. Chen $\mathrm{CZ}$, Ou CY, Wang WL, et al. Using post-bronchodilator FEV1 is better than pre-bronchodilator $\mathrm{FEV}_{1}$ in evaluation of COPD severity. COPD. 2012;9:276-280.
International Journal of COPD

\section{Publish your work in this journal}

The International Journal of COPD is an international, peer-reviewed journal of therapeutics and pharmacology focusing on concise rapid reporting of clinical studies and reviews in COPD. Special focus is given to the pathophysiological processes underlying the disease, intervention programs, patient focused education, and self management protocols.

\section{Dovepress}

This journal is indexed on PubMed Central, MedLine and CAS. The manuscript management system is completely online and includes a very quick and fair peer-review system, which is all easy to use. Visit http://www.dovepress.com/testimonials.php to read real quotes from published authors. 